\title{
Changes in gene expression as one of the key mechanisms involved in radiation-induced bystander effect (Review)
}

\author{
MYKYTA SOKOLOV and RONALD NEUMANN
}

Department of Radiology and Imaging Sciences, Clinical Center, National Institutes of Health, Bethesda, MD 20892, USA

Received February 16, 2018; Accepted May 21, 2018

DOI: $10.3892 / b r .2018 .1110$

\begin{abstract}
The radiation-induced bystander effect (RIBE) refers to the manifestation of responses by non-targeted/non-hit cells or tissues situated in proximity to cells and tissues directly exposed to ionizing radiation (IR). The RIBE is elicited by agents and factors released by IR-hit cells. The growing body of data suggests that the underlying mechanisms of the RIBE are multifaceted depending both on the biological (characteristics of directly IR-exposed cells, bystander cells, intercellular milieu) and the physical (dose, rate and type of IR, time after exposure) factors/parameters. Although the exact identity of bystander signal(s) is yet to be identified, the published data indicate changes in gene expression for multiple types of RNA (mRNA, microRNA, mitochondrial RNA, long non-coding RNA, small nucleolar RNA) as being one of the major responses of cells and tissues in the context of the RIBE. Gene expression profiles demonstrate
\end{abstract}

Correspondence to: Dr Mykyta Sokolov, Department of Radiology and Imaging Sciences, Clinical Center, National Institutes of Health, 9000 Rockville Pike, Bethesda, MD 20892, USA

E-mail: sokolovm@mail.nih.gov

Abbreviations: IR, ionizing radiation; RIBE, radiation-induced bystander effect; ROS, reactive oxygen species; RNS, reactive nitrogen species; LET, linear energy transfer; DDR, DNA damage response; DSB, double-strand break; NGS, next generation sequencing; GJIC, gap junction intercellular communication; SOD, superoxide dismutase; JNK, c-Jun N-terminal kinase; GO, gene ontology; PKC, protein kinase $\mathrm{C}$; NHF, normal human fibroblast; NF- $\kappa \mathrm{B}$, nuclear factor- $\kappa \mathrm{B}$; MT, metallothionein; ICM, ionizing radiation-conditioned medium; miRNA/miR, microRNA; RT-qPCR, reverse transcription-quantitative polymerase chain reaction; $\mathrm{H} 2 \mathrm{AX}, \mathrm{H} 2 \mathrm{~A}$ histone family member $\mathrm{X}$; TGF- $\beta 2$, transforming growth factor- $\beta 2$; TNFRSF6, tumor necrosis factor receptor superfamily member 6; EBV-B, Epstein-Barr virus-infected $\mathrm{B}$ [cells]; GFP, green fluorescent protein; EV, extracellular vesicle; hSC, human stem cell; hMSC, human mesenchymal stem cell; MEF, mouse embryonic fibroblast; snoRNA, small nucleolar RNA; lncRNA, long non-coding RNA; NO, nitric oxide; NOS, nitric oxide synthase; UV, ultraviolet; JA, jasmonic acid; 3D, three-dimensional; FIR, fractionated ionizing radiation

Key words: ionizing radiation, bystander effect, transcriptional changes, DNA damage response, gene expression a high degree of variability between distinct bystander cell and tissue types. These alterations could independently, or in a signaling cascade, result in the manifestation of readily observable endpoints, including changes in viability and genomic instability. Here, the relevant publications on the gene candidates and signaling pathways involved in the RIBE are reviewed, and a framework for future studies, both in vitro and in vivo, on the genetic aspect of the RIBE is provided.

\section{Contents}

1. Introduction

2. $\alpha$-Particles are capable of triggering gene expression changes in bystander cells

3. RIBE-induced changes in gene expression in cells following low-LET IR exposures via media transfer and/or co-culture

4. Changes in gene expression in non-vertebrates triggered by the RIBE

5. RIBE-induced changes in gene expression in tissues/organisms following both high-LET and low-LET IR exposures

6. Heavy-ion particles are capable of eliciting gene expression alterations in bystander cells

7. Conclusions

\section{Introduction}

Until the last decade of the 20th century, it had generally been considered that key biological effects of ionizing radiation (IR) exposures arose as a direct consequence of DNA damage occurring in IR-hit cells that had not been correctly restored by metabolic repair processes (1). However, the dogma that genetic alterations are restricted to directly irradiated cells has been challenged by observations demonstrating that IR exposures are capable of eliciting numerous important biological effects, including cell death; reactive oxygen species (ROS) and reactive nitrogen species (RNS) production; DNA double-strand breaks (DSBs), mutations, chromosomal aberrations and micronuclei induction; genomic instability; and gene expression changes, in cells not directly exposed to IR (2-9). The existence of such a phenomenon, currently known as the radiation-induced bystander effect (RIBE), has 
been documented for different types of IR (including $\alpha-, \beta-, \gamma-$, $\mathrm{X}$-rays, heavy ions) and distinct tissues and cells; and it is highly relevant to low and ultra-low doses of IR, even within the $\mathrm{mGy}$ dose range (10-20). The RIBE elicits, in many cases, long-term, persistent and transmissible alterations that lead to delayed cell death and sometimes neoplastic transformation (21). Since the RIBE has been associated with carcinogenesis, it may have significant implications for the estimation of risk associated with IR exposures. The nature of the RIBE signal and how it influences the non-hit cells remains to be determined. Examination of the alterations in gene expression may provide clues to understanding the mechanisms of the RIBE and delineate the signaling pathways implicated in the sustained damage to these cells. High-throughput DNA microarray technology and, more recently, next-generation sequencing (NGS) techniques may serve as valuable tools of choice to gain insight into the cellular pathways resulting in the RIBE. The phenotypic expression of untargeted effects and the potential consequences of these effects in tissues reflect a balance between the type of bystander signal(s) produced and the responses of cell populations to such signal(s), both of which may be significantly affected by cell/tissue type and genotype. Although the RIBE has been well defined in a number of in vitro models using different endpoints, such as survival, mutations, apoptosis, chromosomal aberrations, DNA DSBs, neoplastic transformation (2-9), the manifestations and possible mechanisms of the RIBE, particularly in vivo, are still not comprehensively understood. In the present review, the involvement of gene expression changes in the RIBE is discussed in the context of various in vitro and in vivo model systems including rodents, fish and plants. This aimed to review the hypothesis that, in addition to targeted effects of damage induced in cells directly hit by IR, a variety of untargeted effects may also make important short-term and long-term contributions to determining overall outcome following IR exposures.

\section{2. $\alpha$-Particles are capable of triggering gene expression changes in bystander cells}

One of the earliest reports demonstrating the involvement of gene expression changes in manifestation of the RIBE was published in 1998 (22). The authors identified that the levels of expression of proteins including p53 and p21(Waf1) were increased (up to 1.4-fold, and 5.5-fold, respectively), whereas the cell-cycle related proteins p34cdc2, cyclin B1 and rad51 were decreased (by 5-6-fold) in confluent, density-inhibited normal human fibroblast populations exposed to $\alpha$-particles with the doses ranging from $0.6 \mathrm{cGy}$ to $1 \mathrm{cGy}$, where only a small fraction of the total cell population nuclei (less than $8 \%$ ) were hit by an $\alpha$-particle track. Notably, it was demonstrated that the expression of p53 and p21 was significantly decreased in the presence of the gap junction inhibitor lindane and in IR-exposed low-density fibroblast cultures (22). The RIBE-induced gene expression alterations were observed in five different strains of fibroblast cultures, demonstrating the existence of a general phenomenon. Additionally, immunocytochemical analysis revealed that the RIBE manifested itself in isolated clusters of neighboring cells (22). In later study, the same group presented direct data indicating the involvement of connexin43-mediated gap junction intercellular communication (GJIC) in the transmission of damage signals to non-hit cells. The use of cells genetically compromised in their ability to perform GJIC allowed demonstration of the upregulation of the stress-inducible p21(Waf1) protein in clusters of directly adjacent cells exceeding the fraction of cells whose nuclei had been traversed by IR exclusively in GJIC-competent cells (23). These alterations in p21(Waf1) expression were accompanied with the induction of DNA damage response (DDR) as evidenced by increased Ser-15 phosphorylation of p53. Therefore, these pioneering RIBE studies at the level of gene expression suggest that similar signaling pathways are induced in bystander cells that are not traversed by $\alpha$-particle as in directly hit cells, and that biological effects in cell cultures are not restricted to the response of individual cells to the DNA damage they receive. The non-irradiated bystander cells may participate in the overall response of confluent density-inhibited populations of cultured human cells. It has also been demonstrated that the RIBE may be suppressed by cell incubation with superoxide dismutase (SOD) as well as an inhibitor of NADPH oxidase, suggesting the effect may be mediated, at least in part, by oxidative stress (24). The signaling pathways involved in oxidative stress responses, including stress-related kinase and transcription factor pathways, have been examined in bystander cells by western blotting, immunocytochemistry and electrophoretic mobility shift assays; a 2-4-fold increase in the phosphorylation levels of c-Jun N-terminal kinase (JNK), extracellular signal-regulated kinases $1 / 2$, ribosomal protein S6 kinase $\alpha-1$, ETS transcription factor and activating transcription factor 2 was observed (24). These observations implicate the activation of an array of signal transduction pathways in bystander cells, involving DDR genes as well as genes involved in transducing the damage signaling from the cytoplasmic membrane and oxidative stress.

A pioneering study examining gene expression profiles covering 2,400 transcripts with high-throughput techniques, including DNA microarray, using confluent human normal fibroblast cultures irradiated with low fluences of $\alpha$-particles, was performed by Azzam et al (25). The results demonstrated that IR exposures elicited a major induction of GJA 1 expression. Elevated levels of GJAl transcripts in cells from IR-exposed cultures correlated with increased levels of the corresponding connexin 43 protein by approximately $4 \mathrm{~h}$ after as low as 0.16 cGy of IR, and also in cells exposed to $\gamma$-rays (25). Exposure to these stresses also resulted in post-translational modification of connexin43; increased phosphorylation of this protein was observed. Upregulation of connexin43 expression in IR-exposed cells correlated with functional communication through gap junctions, as evidenced by dye transfer from irradiated to nonirradiated cells. Overall, these data suggested a critical role for genes involved in GJIC in mediating the cellular responses to IR exposures in the context of the RIBE (25).

Later, it was identified that when only $0.02 \%$ of human HepG2 hepatoma monolayer cells were exposed to $\alpha$-particle IR, thus leaving the remaining $99.98 \%$ of the population as bystander cells, a significant increase in the expression of stress response genes, including CDKN1A and TP53 (both more than 30-fold), CAT (more than 4-fold), HMOX1, SOD1 (both almost 4-fold) and GPX1 occurred in a bulk cell culture (26). Notably, the addition of $\alpha(1)$-microglobulin abolished the induction of 
these genes (26). These data implicate the role of oxidative stress in mediating the RIBE in HepG2 cells.

A DNA microarray technique was used to profile the transcriptome of $\alpha$-particle-irradiated (1 Gy dose) and bystander H1299 cells with diminished protein levels of RAD9 checkpoint clamp component A (27). The RIBE was demonstrated to be associated with a distinct transcriptomic profile. In this study, 254 genes were scored as differentially expressed in bystander H1299 cells, among which only four genes exhibited more than 2-fold upregulation (GIPC3, ZNF480, CHACl and $M Y H 16)$, and four genes exhibited more than 2-fold repression (including SNORA33 and KRTAP5-10) (27). The Gene Ontology (GO) analysis identified RNA metabolism and cell organization as being the most affected biological processes at the transcriptional level of regulation in bystander cells. Notably, the findings implicate changes in transcription as being directly associated with the RIBE manifestations, including genomic instability, since in the bystander populations with no changes in transcription, the increase in micronuclei did not occur (27).

Protein kinase $\mathrm{C}(\mathrm{PKC})$ isoforms, including $\mathrm{PKC}-\beta \mathrm{II}$, PKC- $\alpha / \beta$, PKC- $\theta$ and PKC- $\varepsilon$, have been demonstrated to be induced as part of the RIBE in human cells (28). Notably, DNA microarray studies revealed an increase of up to 3-fold in PRKCE in bystander normal human fibroblasts (NHFs) that were co-cultured for $3 \mathrm{~h}$ with cells exposed to $5 \mathrm{~Gy}$ of $\alpha$-particles (28). Furthermore, small interfering RNA-triggered silencing of $P R K C E$ resulted in significant reduction (up to 1.7-fold) in the occurrence of micronuclei, implying $P R K C E$ involvement in mediating the RIBE in this setting.

To examine the timing of gene expression alterations in bystander IMR-90 fibroblasts, Ghandhi et al (29) studied genome-wide transcriptional profiles between 0.5 and 4 $\mathrm{h}$ after exposure of cells to $0.5 \mathrm{~Gy}$ of $\alpha$-particle IR. There were 407 genes differentially expressed in bystander cells, among which 293 transcripts were responsive to both direct IR exposures and bystander signaling. GO analysis revealed that biological processes, including protein modification, cell surface receptor-mediated signal transduction, cell motility and ion transport, were significantly affected by the RIBE signaling in IMR-90 cells (29). Additionally, the time-dependent expression of genes demonstrated consistent upregulation of SERPINB2 (5-fold induction), interleukin IL8 (4.3-fold) as well as matrix metalloproteinases $M M P 3, M M P 1$ and $M M P 10$, IL6 and IL33, GDF15, LIF and others (29). Thus, the data indicate that the RIBE may trigger global, genome-wide gene expression changes at $0.5 \mathrm{~h}$ post-IR exposure, with a second wave of induction/repression for many genes peaking at 4-6 h post-exposure. A notable finding from this work was that the majority of genes differentially expressed following $\alpha$-particle IR exposures were common to both directly hit and bystander cell populations, suggesting the similarity of signaling pathways triggered by direct IR exposure and the RIBE at the level of transcriptional changes.

Later this group examined a time-series of gene expression alterations following $0.5 \mathrm{~Gy}$ of $\alpha$-particle IR in IMR-90 human fibroblast cells at $0.5,1,2,4,6$ and $24 \mathrm{~h}$ post-exposure (30). In bystander cell cultures, $\mathrm{GO}$ analysis revealed gene clusters that were overrepresented for biological processes including ligand-mediated signaling, cell communication and cell motility, and immunity and defense. Network studies confirmed the involvement of p53 and nuclear factor- $\kappa \mathrm{B}$ $(\mathrm{NF}-\kappa \mathrm{B})$ transcription factor-modulated gene clusters in both directly IR-exposed and bystander cells (30). Notably, gene expression profiles of the metallothionein (MT) superfamily (including $M T 1 B, M T 1 G, M T 1 E, M T 1 L$ ) were significantly changed in both directly irradiated and bystander cells, suggesting the commonality of regulation in these populations. Certain novel factors, including lysine demethylase $5 \mathrm{~B}$ and histone deacetylase 1 and 2, which could epigenetically control gene expression after IR exposures, were identified by Feature Based Partitioning Around Medoids Algorithm (FBPA) (30). Notably, the data illuminated the importance of both the epigenetic control of gene expression changes and transcription factor networks in potentiating the RIBE in human cells (30).

The cytokine gene expression profiles of IL33, IL8, IL6 and PTGS2 in bystander human skin fibroblasts immortalized with simian virus 40 T-antigen, and in IMR-90 normal human cells, have been found to exhibit marked similarities with those in cells directly exposed to 0.5 Gy of $\alpha$-particle IR (31). The biphasic changes were observed for many of these genes with the early peak (0.5-1 h) and late induction (6-24 h). The fold-changes for certain genes, including IL33, ILIB, MMP3 and $I L 8$, were even higher in bystander cells (up to 12-fold for IL33) than in directly IR-exposed IMR-90 fibroblasts (up to 10-fold for IL33) (31). This data demonstrated the early activation of $\mathrm{NF}-\kappa \mathrm{B}$-dependent gene expression first in directly irradiated cells and only then in bystander cells.

The RIBE transcriptional responses in human F11 fibroblasts exposed to $0.1 \mathrm{~Gy}$ of $\alpha$-particle IR have been studied using whole-genome DNA microarray analysis (32). Bystander cells were cultured in IR-conditioned media (ICM) harvested from irradiated immortalized human F11 fibroblasts for either 4,8 or $26 \mathrm{~h}$ post-IR. Interestingly, the authors observed no genes with significantly altered levels of expression in bystander F11 fibroblasts at any of the time points; however, 43 genes exhibited minor down-regulation (0.65-0.9-fold changes compared to sham-treated control) only at the earliest $4 \mathrm{~h}$ time-point (32). Therefore, only minor RIBE transcriptional responses occurred under these experimental conditions, suggesting that the RIBE magnitude may depend on multiple factors, many of which still need to be elucidated.

The involvement of epigenetic mechanisms in the RIBE has been substantiated in a study that co-cultured bystander WS1 human fibroblasts with $\mathrm{HaCaT}$ keratinocytes traversed by $\alpha$-particles at a dose of $0.56 \mathrm{~Gy}$ (33). The expression of microRNA (miRNA/miR)-21 was increased in the bystander WS1 cells (up to 1.2-fold), and the ectopic repression of miR-21 abrogated the RIBE. Notably, miR-21 targets SOD2 (34), implying that miR-21 may potentiate the RIBE through oxidative stress regulation (33).

Certain studies into the RIBE have utilized specialized equipment $(9,10,35,36)$, including a device that can place known numbers of charged particles (such as $\alpha$-particles or protons) at defined positions relative to individual cells. These narrow beams of IR, usually of micrometer or submicrometer dimensions, are generally delivered by so-called microbeam devices (37). Thus, using this equipment it is possible to evaluate individual cell IR responses in both directly hit and 
bystander cells in the same culture. CDKN1A transcriptional changes have been examined at a single-cell level in normal human fibroblasts following delivery of 0 or $10 \alpha$-particles per cell to $50 \%$ of cells in a bulk population (38). By using reverse transcription-quantitative polymerase chain reaction, (RT-qPCR), it was identified that both directly IR-exposed and bystander fibroblasts exhibited increases in the levels of CDKN1A mRNA at $1 \mathrm{~h}$ post-IR, corresponding to 7 and 2.8-fold overexpression of transcript levels relative to sham-treated cell cultures (38).

The manifestation of genomic instability upon the RIBE suggests that at least under certain conditions, the formation of DNA DSBs may be involved as a step underlying the mechanisms of the RIBE. Formation of DSBs induces the phosphorylation of $\mathrm{H} 2 \mathrm{~A}$ histone family member X (H2AX) at serine 139 residue, and this phosphorylated form, termed $\gamma$-H2AX, is known to form foci at sites of DNA DSBs (39). Our group previously reported that irradiation of cultured human cells resulted in $\gamma$-H2AX foci formation in bystander cell populations (9). To the best of our knowledge, our study was the first to demonstrate that the RIBE may be accompanied by increases in the fraction of cells in a bulk population containing multiple $\gamma$-H2AX foci. For example, following 18 $\mathrm{h}$ co-culture with cells hit with $20 \alpha$-particles, the fraction of bystander cells bearing multiple $\gamma-\mathrm{H} 2 \mathrm{AX}$ foci increased by approximately 3.7-fold (9). Notably, this effect was reproduced in bystander cells mixed with cells irradiated with $\gamma$-rays, and in cell populations growing in ICM, albeit at somewhat lower magnitude (9). That c-PTIO and aminoguanidine, which are known to decrease nitric oxide (NO) levels, abolished the RIBE in both sets of experiments suggested that gene expression changes may be involved (40). Therefore, our group's studies implicated multiple mechanisms that may underlie the RIBE.

That the indirect biological effects of IR exposures may be mediated by ROS and RNS was proposed more than two decades ago $(41,42)$. Our group identified that NO scavenging markedly affected the gene expression changes in normal human IMR-90 fibroblasts following $\gamma$-rays (40). Indeed, a greater than 7-fold decrease in the number of induced genes upon NO depletion was detected compared to control cell cultures (40).

Our group and others have reported that DNA DSBs, directly measured by the $\gamma-\mathrm{H} 2 \mathrm{AX}$ focus formation assay, accumulate in bystander cells in a number of experimental systems including human cultured cells, human three-dimensional tissue models and in mice $(9,3,43,44)$. In addition, our previous study demonstrated that various other sources of cell stress, including media from cancerous cells, resulted in a DNA DDR in normal human cells that was reminiscent of the RIBE (43). These findings suggested that the RIBE may be part of a more general stress response; however, the molecular mechanism underpinning the RIBE remain unclear. Nonetheless, H2AX phosphorylation may be involved in the earliest stages of the RIBE, and formation of DNA DSBs may be responsible as an upstream effector mechanism in the RIBE, induced by both high-linear energy transfer (LET) $\alpha$-particles and low-LET $\gamma$-rays.

3. RIBE-induced changes in cellular gene expression following low-LET IR exposures via media transfer and/or

\section{co-culture}

One of the key transcription factors involved in a modulation of gene expression in response to a variety of stresses inducing either growth arrest or apoptosis in damaged cells is p53 encoded by the TP53 gene (45). Previous comparative analysis of the spectra of IR-responsive genes in cells of different origin and p53 status using a DNA microarray technique identified several known secreted growth inhibitory factors, including the genes for insulin-like growth factor-binding protein 2, transforming growth factor- $\beta 2$ (TGF- $\beta 2)$ and others (46). Indeed, a p53-dependent accumulation of proteins, which causes growth suppression in a variety of cell lines, has been reported to occur following IR exposure in the media from established and primary human cell cultures (46). These findings imply that p53 induction may potentially elicit the RIBE by triggering the transfer of growth suppressive factors from IR-exposed cells to neighboring undamaged cells.

Resident proteins that reside on the plasma membrane are exfoliated from the cell surface; such exfoliation is a selective, energy-dependent process that mediates intercellular communication (47). IR exposures have been demonstrated to modulate the expression of several plasma membrane-bound growth regulators, including the 'death' ligand, tumor necrosis factor receptor superfamily member 6 (TNFRSF6) (47). For example, IR induced dose-dependent upregulation of TNFRSF6 on plasma membranes purified from the SW620 colon cancer cell line; suggesting that IR increases the level of TNFSF6 exfoliated on extracellular vesicles (EVs) (47). Such data may provide a basis for identifying mechanisms underpinning abscopal effects and the RIBE following IR exposures.

One of the earliest studies in gene expression using ICM collected from HFL1 normal human diploid lung fibroblasts exposed to 2 Gy of IR as a model RIBE system was reported approximately a decade ago (48). The DNA microarray data demonstrated that the gene expression profile in IR-exposed fibroblasts was radically different from that in non-IR-exposed bystander cells, implying that the molecular pathways leading to the RIBE are distinct from those occurring in the directly IR-hit cells. A number of genes responsible for cell communication processes and extracellular signaling, including growth factors and receptors, were identified to be induced in bystander cells. For example, the AREG, IL11, EREG, $F G F 7, R G S 2$ and FN1 genes were overexpressed only in cells receiving ICM harvested from IR-exposed cells, but not in IR-hit fibroblasts (48). Notably, the magnitude of transcriptional changes in this specific model system was generally modest, with genes being overexpressed less than 2.1-fold compared with in sham-treated cell populations (48).

The medium transfer approach was used in later study to investigate the role of IL8 and IL8 receptor encoded by C-X-C motif chemokine receptor $1(C X C R I)$ in the RIBE following $\gamma$-irradiation of T98G cells (49). The data implied that both the ability to release IL8 and the IL8 receptor expression status were important in determining the RIBE. ELISA demonstrated that the expression of CXCR1 was significantly increased in bystander cells cultured for $20 \mathrm{~h}$ with ICM collected from T98G cells exposed to 0.5 and 1 Gy of $\gamma$-rays (49). However, the levels of CXCRI mRNA were not quantified in the study, 
leaving it undetermined as to whether these changes were occurring on transcriptional or posttranscriptional levels.

The RIBE transcriptional responses in human F11 fibroblasts exposed to 2 Gy of $\gamma$-IR were studied using whole-genome DNA microarray analysis (50). When the F11 cells were exposed to IR and ICM was transferred to bystanders, only one gene, namely LGALS3 was differentially expressed with a minor 1.2-fold induction as a result of the RIBE (50). GO analysis on a subset of genes with small changes in expression identified ribosome and oxidative phosphorylation pathways as being somewhat affected (50); however, the transient nature of minor gene-set enrichment (only at $8 \mathrm{~h}$ post-IR) may have had a direct impact on the magnitude of the RIBE observed.

The role of miRNA in the RIBE has recently become a topic of interest since the RIBE has been postulated to be epigenetically controlled by miRNAs $(33,44,51-53)$, which target mRNA transcripts for inhibition by means of interfering with translation. Notably, human Epstein-Barr virus-infected B (EBV-B) cells in co-culture with IR-exposed human bone marrow mesenchymal stem cells (hMSCs) exhibited profound RIBE (54). DNA array and RT-qPCR were used to elucidate changes in gene expression in the RIBE, and the authors observed induction of SERPINB2 (1.7-fold) in EBV-B cells after $1 \mathrm{~h}$ of co-culture with IR-exposed hMSCs. By contrast, miRNAs let-7a1, miR-15b and miR-21 were downregulated in EBV-B cells co-irradiated with hMSCs (54). These data imply changes in both mRNA and miRNA as part of a regulatory mechanism governing the RIBE.

Mitochondrial gene transcriptional changes in human lymphoblast TK6 cells exposed to 2 Gy of X-rays have been reported to be modulated as a result of the RIBE in an insert co-culture system (55). Specifically, MT-ND1, MT-ND5 and $M T-N D 6$ encoding NADH dehydrogenases were repressed in bystander cells, whereas the MT-ATP6 and MT-ATP8 genes encoding ATP synthases were induced in bystander cells (55). These data implicate mitochondrial gene expression changes in the manifestation of the RIBE and suggest that the mitochondrial gene expression response is an essential part of a complex stress response triggered by IR exposures.

Subsequent experiments using TK6 cells grown in ICM identified notable miRNA expression alterations (51). The let-7 family of miRNAs was mostly repressed in bystander cells, as were miR-17-3p, miR-19b, miR-15a, miR-16, miR-155 and miR-21 and miR-18a species (51). The miRNAs miR-17-5p, miR-142-3p, miR-142-5p and miR-19a were only transiently upregulated in bystander cells, whereas the induction of miR-143 and miR-145 expression was more sustained over time (51). These results imply the participation of several miRNAs involved in $R A S, c-M Y C$ and $B C L 2$ gene regulation in the RIBE (51).

Later, the transcriptional changes of both a number of small nucleolar RNAs (snoRNAs) and long non-coding RNAs (lncRNAs) in IR-exposed and bystander TK6 cells grown in ICM were examined to elucidate the molecular pathways triggered in these cells (56). The snoRNA host genes SNHG1, SNHG4, SNHG5 and SNHG11 were downregulated in bystander cells; furthermore, lncRNAs including $S R A 1$, MALAT1, MATR3 and SOX2OT were repressed in bystander TK6 cells. By contrast, the lncRNA RMST was upregulated in both IR-exposed and bystander cells (56). This data suggests that expression levels of non-coding RNAs may be affected in both IR-exposed and bystander cells; in addition, these gene expression alterations may be associated with the RIBE (56).

One of the key manifestations of the RIBE is an induction of complex apoptotic cascades in bystander cells. In one study, human keratinocyte HaCaT cells were exposed to $\gamma$-IR at doses of 0.05 and $0.5 \mathrm{~Gy}$, and then ICM was transferred to bystanders either 1 or $24 \mathrm{~h}$ later (57). The authors reported a marked induction of TP53 (more than 60-fold; after 0.05 Gy IR and $1 \mathrm{~h}$ of ICM exposure), pro-apoptotic $B A X$ (more than 50-fold; after 0.05 Gy IR and $24 \mathrm{~h}$ of ICM exposure) and initiator caspase CASP2 (more than 14-fold; after 0.05 Gy IR and $1 \mathrm{~h}$ of ICM exposure), among others (57). Notably, the gene expression profile in the RIBE was distinct and more complex in comparison to direct IR exposure responses. Thus, in the RIBE there may be robust induction of the apoptotic cascade via upregulation of key genes underlying the programmed cell death response, suggesting major involvement of transcriptional machinery in manifestation of the RIBE in HaCaT cells.

The RIBE has been investigated between genetically similar and non-similar cells in relation to the role of inducible NO synthase (NOS) in intercellular communications (58). Both RAW 264.7 (macrophage) and EL-4 (lymphoma) cell cultures were exposed to 5 Gy $\gamma$-IR and ICM from irradiated cells was harvested and transferred to bystander cells. Bystander EL-4 cells demonstrated an upregulation of the TP53 (approximately 3.8-fold), CDKN1A (1.6-fold) and NOS2 (1.5-fold) genes. In addition, bystander EL-4 cells exhibited an increase in NO production. Notably, irradiated RAW 264.7 cells did not trigger the RIBE in bystander EL-4 cells. Treatment of EL-4 or RAW 264.7 cells with L-NAME, an inhibitor of NO synthesis, significantly reduced the induction of gene expression and DNA damage in the bystander EL-4 cells, whereas treatment with carboxy-PTIO, an NO scavenger, only partially reduced the induction of gene expression and DNA damage in the bystander EL-4 cells (58). Therefore, active NOS 2 in the irradiated cells was indicated to be essential for the RIBE (58). Furthermore, the genotype of cells appeared to be one of the major factors affecting transcriptional response in the RIBE.

A DNA microarray technique was used to examine the genome-wide gene expression changes in human melanoma Me45 cells grown in ICM for $36 \mathrm{~h}$ (59). ICM was prepared by cell culture conditioning for $1 \mathrm{~h}$ of cells exposed to 4 Gy of IR. Transcripts for approximately 5,700 genes were upregulated and for 5,000 genes repressed in bystander Me45 cells, with certain genes exhibiting more than 2-fold changes in expression levels compared with a sham-treatment group (including $G A B B R 1, G A L R 3, A M H R 2, K I T$ ) (59). Notably, the authors identified that more than $87 \%$ of differentially expressed genes were shared between bystander cells and cells directly exposed to IR. GO analyses indicated that receptor interactions, calcium signaling and cell communication were predominantly activated in bystander cells, whereas purine metabolism, oxidative phosphorylation and cell cycle were among the most downregulated processes in bystander Me45 (59). Furthermore, these gene expression changes could last for more than one cell cycle (59), which may have implications with regard to the long-term effects of IR exposures.

Another research group observed the similar trend in genome-wide transcript levels in K562 human erythroleu- 
kemia cells grown for $36 \mathrm{~h}$ both after direct 4 Gy X-ray IR exposures and following ICM-triggered RIBE (60). Notably, approximately $72 \%$ of genes changed similarly in directly IR-exposed and bystander K562 cells, whereas less than $1 \%$ exhibited a non-coherent response (60). However, the vast majority of differentially expressed genes exhibited only modest changes in expression, with only a number of genes being upregulated more than 2-fold compared with in sham-treated controls, including STK38 (5.5-fold), HSPC111 (3.9-fold) and INVS (3.5-fold), among others (60). GO studies indicated the most affected biological processes in bystander cells to belong to cytokine-cytokine receptor interaction, neuroactive ligand-receptor and Janus kinase/signal transducer and activator of transcription signaling. Therefore, the gene expression profiles of bystander cells grown in ICM and directly irradiated cells may undergo notably similar changes.

The transcriptional response in the RIBE has been studied in a U87MG multicellular tumor spheroid model grown in the ICM harvested from cells exposed to 4 Gy of X-rays (61). Statistically significant downregulation of pro-survival BCL2 (up to 3-fold repression compared with control) was observed in bystander cells at 4 and $24 \mathrm{~h}$ post-ICM transfer. In contrast, pro-apoptotic JNK was induced approximately 1.6-fold during manifestation of the RIBE in these cells at $4 \mathrm{~h}$ post-ICM transfer (61). Changes in the expression of genes implicated in apoptosis indicate involvement of both extrinsic and intrinsic pathways in mediating the RIBE at the level of transcription.

Limited studies thus far have investigated the RIBE induced by exposure to high doses of IR. In one such study, spatially fractionated radiation (GRID) treatment was demonstrated to trigger changes in GRID bystander areas in SCK and SCCVII murine carcinoma cell lines following a single IR dose of 10 Gy (62). The bystander cells were defined as GRID adjacent cells that received approximately 1 Gy scatter dose or, in a separate subset of experiments, non-irradiated cells exposed to ICM. The gene expression signature for stress response signaling in SCCVII cells at 4- and 24-h post-GRID exposure revealed a significant (more than 3-fold) upregulation of several DDR and stress signaling genes, among them Hspa4, Gpx1, Dnaja1, Lig1, Xrcc1, Msh1, Mlh1, Hus1 and Exol, suggesting an extended network of pathways triggered in response to the RIBE (62).

The RIBE was potently elicited in human fetal lung MRC-5 fibroblasts grown in ICM harvested from cells exposed to 2 Gy of X-rays (53). Gene expression profiling with Solexa sequencing revealed a set of differentially expressed miRNAs in the cell culture medium after IR exposures, among which miR-21 species exhibited the highest (1.23-fold) level of induction. The overexpression of $\mathrm{miR}-21$ resulted in a repression of its direct target gene BCL2 (53). These data indicated that miR-21 may be involved in the RIBE (53), perhaps by modulating the threshold required for apoptosis induction, at least in some types of cell. At a similar time, it was demonstrated that another miRNA species, miR-663a, may be involved in the regulation of the RIBE through its targeting of TGF- $\beta 1$ (52). In HeLa cells cultured for $12 \mathrm{~h}$ in ICM collected from cells directly exposed to 4 Gy of X-rays, miR-663a was induced more than 4-fold compared with in sham-treated controls (52). The authors proposed that miR-663a upregulation results in repression of TGF- $\beta 1$ that, in turn, may limit the RIBE.
The importance of extracellular miRNAs triggered by IR in the RIBE has been recently reported (63). An miRNA DNA array analysis was conducted using A549 lung cancer cells grown in ICM collected from cells exposed to $4 \mathrm{~Gy}$ of IR. The authors identified that 17 miRNAs were induced more than 2-fold while four miRNAs were downregulated by IR (63). Among these, let-7i-5p, miR-17-5p, miR-24-3p, miR-92a-3p, miR-1246 and miR-2861 were shown to be highly IR-responsive. The extracellular miR-1246 could transfer from donor IR-exposed cells to bystander cells via ICM and directly affect death receptor 5 expression level in bystanders. These data suggest that extracellular miR-1246 may serve as a component of the RIBE signaling cascade between IR-exposed and non-irradiated cells (63).

The global gene expression signatures of bystander v-src-transformed $208 \mathrm{~F}$ rat fibroblasts cultured in ICM harvested from cells exposed to $0.5 \mathrm{~Gy}$ of IR have been studied (64). The data indicated the predominant induction of genes related to growth factors and interleukin-related signaling pathways in the RIBE in these cells (64).

A marked difference in transcriptional responses has been observed in bystander human colorectal carcinoma HCT116 cells harboring either wild type or knockout TP53 using a Transwell co-culture system (65). Following 4 Gy IR exposures, the expression level of the $\mathrm{NF}-\kappa \mathrm{B}$ inhibitor $N F K B I A$ was increased in TP53-/- cells at the earliest time points (up to 4 -fold at $3 \mathrm{~h}$ post-treatment), whereas in wild-type HCT116 cells an upregulation of NFKBIA (up to 3-fold) was observed only after $6 \mathrm{~h}$, which reduced to control level by $24 \mathrm{~h} \mathrm{(65)}$. These data imply the direct involvement of p53-dependent signaling pathways in the transcriptional response of human cells during the RIBE.

It was hypothesized by our group that the RIBE may be a specific type of intercellular communication occurring between damaged and undamaged cells regardless of damage source (13). Using $\gamma-\mathrm{H} 2 \mathrm{AX}$ and p53-binding protein 1 foci formation as endpoints, the RIBE was observed to occur primarily in S-phase HeLa cells at earlier times post-UV exposure (up to 7-fold increase in DDR protein foci at 3 h post-exposure) (13). Cell culture media harvested from NHFs exposed to either IR or non-IR as well as conditioned cell culture media from malignant and senescent cells was demonstrated to contain increased levels of several cytokines, including TGF- $\beta$, tumor necrosis factor- $\alpha$ and plasminogen activator inhibitor 1 (13). Notably, the RIBE could be partially reverted by antioxidants, NO synthase inhibitors and TGF- $\beta$ blocking antibody. Thus, the cell culture exposure to cytokines or active compounds released from stressed cells, regardless of damage source, could underpin the formation and manifestation of the RIBE.

It is established that human stem cells (hSCs) are critically involved in numerous key biological processes and mechanisms including, but not limited to, human development, maintenance of normal homeostasis in adult human bodies, and a range of aging-related pathologies including carcinogenesis and others (66). Our group, to the best of our knowledge, was among the first to use both medium transfer and cell co-culture bystander protocols to examine the RIBE in hMSCs and human embryonic stem cells (14). These cells were exposed to X-ray doses of $0.2,2$ and $10 \mathrm{~Gy}$, and then 
ICM was transferred to non-irradiated hSCs for time course studies. In a subset of studies, IR-exposed hMSC were labeled with a vital CMRA dye and co-cultured with bystander hMSC. Surprisingly, a lack of robust RIBE was observed for all experimental conditions and data points in the study, suggesting that the hSC compartment may not be susceptible to RIBE-associated signaling compared with differentiated adult human somatic cells (14). This finding may have implications in the field of radiation biology/oncology, in evaluating radiation risk of IR exposures, and for the safety and efficacy of hSC regenerative-based therapies.

Previously, authors have aimed to distinguish between GJIC and paracrine RIBE signaling. In one report, non-communicating Jeg3 malignant trophoblast cells were transfected with inducible gap junction proteins, connexin43 and connexin26 (67). Then, X-ray-irradiated (5 Gy dose) and non-irradiated bystander Jeg3 cells were co-cultured for $4 \mathrm{~h}$, and the levels of expression of activated p53 and p21 were examined. In this particular model system, the RIBE was independent from GJIC. Thus, the diffusible molecules shed from IR-exposed Jeg3 cells may have been the mechanism responsible for the RIBE in this setting (67).

The RIBE may be induced in cultured mouse embryo fibroblasts (MEFs) 1 day after addition of serum from IR-exposed $\mathrm{C} 3 \mathrm{H}$ and $\mathrm{B} 6 \mathrm{C} 3 \mathrm{~F} 1$ mice (68). The serum of chronically irradiated mice (10 or 20 days of $\gamma$-IR exposure at a dose rate of approximately $0.02 \mathrm{~Gy} / \mathrm{h}$; total body dose 4 or $8 \mathrm{~Gy}$ ) was transferred to MEFs for $24 \mathrm{~h}$, and the gene expression changes were analyzed using whole-genome DNA microarrays. The expression of 112 and 2,689 genes were altered more than 1.5-fold in bystander MEFs cultured with serum collected from 4 Gy and 8 Gy IR-exposed mice, respectively (68). Notably, 29 genes exhibited a more than 5-fold increase in expression level, with a more than 56-fold increase detected for cyclin-dependent kinase 5 activator 1 (68). GO analysis identified protein ubiquitination, nuclear factor (erythroid-derived 2)-like 2-mediated oxidative stress response, actin cytoskeleton, focal adhesion kinase, mitogen-activated protein kinase and insulin receptor signaling pathways among the most affected by the RIBE in bystander MEFs.

\section{Changes in gene expression in non-vertebrates triggered by the RIBE}

The RIBE has been detected not only in vertebrates but also in the phylogenetically oldest metazoan phylum, Porifera. The single cells of the demosponge Suberites domuncula treated with ultraviolet (UV)-B light $\left(40 \mathrm{~mJ} / \mathrm{cm}^{2}\right)$ induced apoptosis in bystander cells in experiments using a two-chamber system (69). Notably, this cell-killing phenomenon was mediated, at least in part, by NO and ethylene. High levels of dimethylarginine dimethylaminohydrolase mRNA were demonstrated to occur in directly UV-exposed cells; and the RIBE could be controlled by both NO and ethylene in this experimental system (69). Therefore, the RIBE may be an evolutionarily ancient mechanism of living beings' response to IR exposures inherent even to some of the most basal metazoans.

Long-range or abscopal RIBE has been reported in plants, for example, in Arabidopsis thaliana (A. thaliana) seeds and embryos (70). One of the first reports addressing whether the RIBE is limited to the specific organ exposed to IR, spans a limited region of the living being, or affects the whole body of the target was published over a decade ago (70). The authors exposed a specific cell group, namely the shoot apical meristem of $A$. thaliana embryo, to a defined number of protons, and then assessed the root development in IR-exposed plants. The data suggested that IR exposure of the shoot apical meristem region resulted in significant primary root elongation, lateral root initiation and root hair differentiation inhibition (70). Thus, the RIBE may exist at the level of the whole organism, at least in plants. Further experiments demonstrated that ROS and/or auxin and auxin-dependent transcription processes elicited by ROS may be implicated in the RIBE in A. thaliana (70). More recently, the expression level of the homologous recombination-related AtRAD54 gene was examined in the context of the RIBE (16). Localized $\alpha$-particle exposure of roots to $10 \mathrm{~Gy}$ of IR triggered a transient, modest (less than 2-fold) induction of $A t R A D 54$ at 12 and $24 \mathrm{~h}$ post-IR in the non-exposed aerial plants (16). In accord with the authors' previous data, the treatment of IR-exposed plants with the ROS scavenger dimethyl sulfoxide significantly diminished the effects of the RIBE on expression of the AtRAD54 gene in bystander plant tissues, reinforcing the earlier observation that ROS may serve a major role in potentiating the RIBE in plants $(16,70)$.

The RIBE triggered by low-energy-ion IR exposures has been revealed to depend on the targeted portion of $A$. thaliana seeds (71). When the seeds were subjected to IR from four defined orientations with $30 \mathrm{keV}(40) \mathrm{Ar}(+)$ ions, the expression of AtRAD54 was induced in aerial plants. Interestingly, the root apical meristem-orientated IR exhibited the greatest effects on the RIBE (up to 2-fold increase in 3-day seedlings), suggesting that the magnitude of the RIBE in whole plants is defined in large by the geometry of the targeted portion of seeds (71). Notably, the modeled microgravity significantly decreased the RIBE-mediated overexpression of the AtRAD54 and AtRAD51 genes in A. thaliana (72).

The involvement of jasmonic acid (JA) signaling in the RIBE in A. thaliana has been recently demonstrated (73). In particular, pretreatment of seedlings with salicylhydroxamic acid, an inhibitor of lipoxigenase in JA biosynthesis, markedly decreased the expression of AtRAD54 in context of the RIBE, resulting in no statistically significant difference compared with sham-treated controls (73). Following IR-exposures of roots, the aerial parts of $A$. thaliana lacking key elements of the JA signaling cascade exhibited decreased expression of the AtRAD54 and AtRAD51 genes, being only slightly higher than in sham-treated control plants. These data imply an involvement of the JA signal pathway in the plant RIBE.

The time course of RIBE signaling, using a root micro-grafting methodology in which the RIBE cell-to-cell communication of root-to-shoot could be manipulated, such as stopped or started at specific times after root IR exposures, has been elucidated in a study by Wang et al (74). Notably, the modulation of the expression level of AtRAD54 during an 8 h-long accumulation of the RIBE signal in bystander parts of A. thaliana following IR exposures suggested a potent RIBE response. The RIBE in this study could be induced simultaneously by multiple types of the RIBE signals triggered at 
different time-points following IR exposures. ROS were also demonstrated to be involved in the RIBE in recipient cells (74).

\section{RIBE-induced changes in gene expression in tissues/ organisms following both high-LET and low-LET IR exposures}

The majority of studies on the RIBE have been performed in single-cell in vitro systems, which remain the most efficient applicable tool for characterizing basic molecular responses in cells. Reports have also described and evaluated the RIBE in explants and in a three-dimensional (3D) normal human tissue model $(12,13)$. However, it is the animal/plant models that can place the RIBE in the context of a complex living organism; therefore, in vivo studies using a microbeam or organ shielding technique represent a crucial step in expanding knowledge of the RIBE. The gene expression alterations have been studied in the brain upon liver IR exposures in a rat RIBE model (44). The RIBE resulted in changes in transcriptional profiles of 22 genes occurring in the prefrontal cortex of female rats ( 21 of them showed repression, among which cadherin- 1 and T-box 18 were markedly downregulated) upon liver IR exposures at 0.125 cGy dose (44). Notably, the RIBE was more robust in females compared with in males, in which only one gene encoding uncharacterized hypothetical protein LOC688613 was observed to be differentially expressed.

Previous experiments in cultured cells have established that NF- $\kappa B$ serves a major role in the RIBE in out-of-target cells (31). To elucidate the involvement of this signaling pathway in the RIBE in vivo, the heart tissues from C57/BL6 mice having lower abdomen areas exposed to single-dose IR ( 2 or $10 \mathrm{~Gy}$ ) or fractionated IR (FIR; 2 Gy per day for 5 days) were studied for bystander/abscopal NF- $\mathrm{BB}$ signal transduction gene expression activity (75). Transcriptional profiling revealed that 51, 46 and $26 \mathrm{NF}-\mathrm{kB}$-regulated genes were significantly (more than 2-fold) induced after 2 Gy, 10 Gy and FIR, respectively. Of these, 22 genes displayed dose- and fractionation-independent upregulation, including Fadd, Casp8, Rela and Tnfrsf10b (75). Together, these data indicated an induced bystander/abscopal response in distant organs, such as the heart, in a mouse model following exposure to clinically relevant IR doses. More notably, it was concluded that orchestration of NF- $\mathrm{\kappa B}$ signal transduction in nontargeted tissues may serve as an effector and could serve a key role in induced RIBE (75).

The epigenetic level of regulation of the RIBE in tissues and in vivo have become a topic of interest in the last decade. Indeed, when miRNAome changes in bystander 3D artificial EpiAirway human tissues following $\alpha$-particle microbeam IR exposure with 5.4 Gy were examined with miRNA microarrays, the deregulation of several miRNA species in bystander tissues was identified (76). The alterations in the miRNAome may mediate persistent changes in gene expression, apoptosis, and cell cycle perturbation aspects of the RIBE. For instance, it was identified that miR-29c was overexpressed almost 2.5 -fold at 3 days post-IR, whereas miR-22 was induced almost 2-fold at $8 \mathrm{~h}$ post-IR in bystander tissues (76). These changes were mirrored by decreased levels of key transcription factors including E2F transcription factor 1 and RB transcriptional corepressor 1 , implying proliferation induction in bystander tissues (76). Upregulation of miR-29 was accompanied by repression of its targets, including DNA methyltransferase $3 \alpha$ and $M C L 1$, a $B C L 2$ family apoptosis regulator, potentially impacting DNA methylation and apoptosis (76).

The role of EVs in mediating the RIBE has been recently studied in vivo in mice (77). C57BL/6 mice were exposed to X-rays at doses of $0.1,0.25$ and $2 \mathrm{~Gy}$. After $24 \mathrm{~h}, \mathrm{EVs}$ were harvested and injected into bystander counterparts. An increase in DNA damage in EV-recipient animals was readily observed. A subset of eight differentially expressed miRNAs was detected in the EVs, among them three induced miRNAs, namely miR-152-3p, miR-199a-5p and miR-375-5p, and five repressed miRNAs, namely miR-33-3p, miR-140-3p, miR-200c-5p, miR-669o-5p and miR-744-3p. Gene network analysis identified that these differentially expressed miRNA genes were implicated in signaling pathways connected to DNA damage and DNA repair, and immune system regulation, implying that these pathways are directly involved in the RIBE in vivo (77). Therefore, the transcripts of certain miRNA genes transferred by EVs may be responsible for the RIBE; however, the pattern of changes could be distinct in the directly IR-exposed and EV-recipient bystander mice, implying unique underlying mechanisms involved (77).

A previous study on the RIBE in vivo involved the exposure of experimental mice heads to IR, while a medical-grade shield was used to protect the body of the animals (78). It was identified that 1 Gy of IR elicited a sex-specific change of the miRNAome in the bystander spleen of mice at 6 and $96 \mathrm{~h}$ post-IR, with repression of miR-24, miR-30e, miR-181a, miR-422b in females and of miR-26b in males. The deregulated miRNA levels were mirrored by sex-specific changes in the levels of the components of the RNA-induced silencing complex and Dicer enzyme (78). More recently, it was demonstrated that exosomes containing miR-7 released from brain tissues of mice exposed to $10 \mathrm{~Gy}$ of IR were capable of inducing marked gene expression alterations in the non-exposed lungs of the animals through repression of BCL2 (79). Collectively the data suggest an important role of the miRNAome in mediating the RIBE in vivo and may serve as a basis for identifying novel RIBE biomarkers.

\section{Heavy-ion particles are capable of eliciting gene expression alterations in bystander cells}

The impact of energetic heavy ion IR exposures on the RIBE remains to be fully characterized; to this end, DNA microarray analysis of directly irradiated and bystander AG01522D fibroblasts in confluent cultures has been performed (80). To study the RIBE, defined sites within cells were targeted with particles of carbon ions (18.3 MeV/u, $103 \mathrm{keV} /$ microm) using microbeams. Regardless of the target numbers $(1,5$ or 25 sites) and the time post-exposure ( 2 or $6 \mathrm{~h}$ post-IR), similar expression changes were observed in bystander cells. Among 874 genes that were differentially expressed in bystander cells, approximately one quarter were upregulated and three quarters repressed (80). Among these were genes related to stress response (EIF2AK4, RAD23B, ATF4), cell cycle regulation (RBBP4, MYCN, NEUROG1) and intercellular communication (FN1, ANXA1, PIK3C2A, GNA13, ILIRAP) (80). Additionally, mediator complex subunit 18 was overexpressed more than 

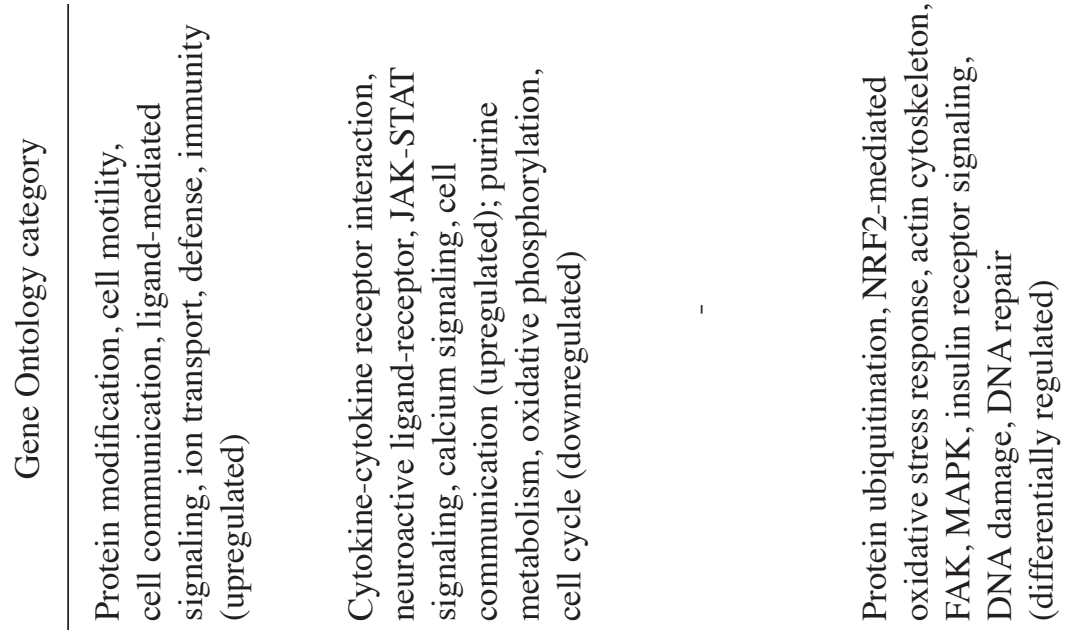

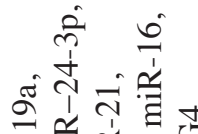

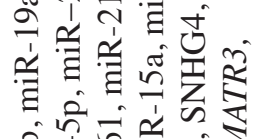

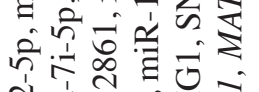

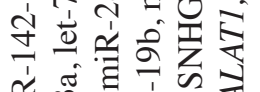
岂

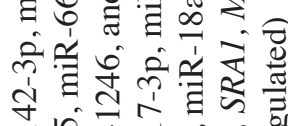

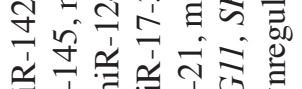

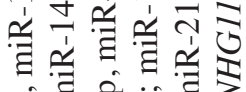
थे के

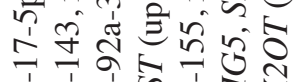

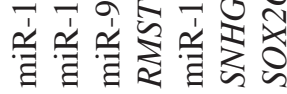

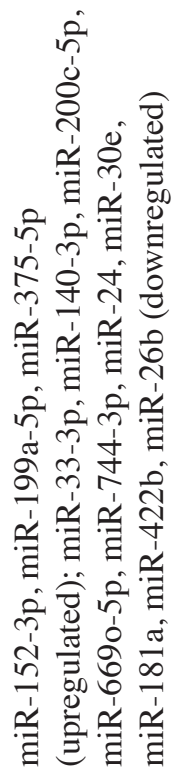

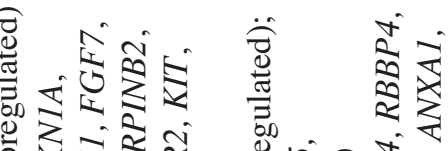

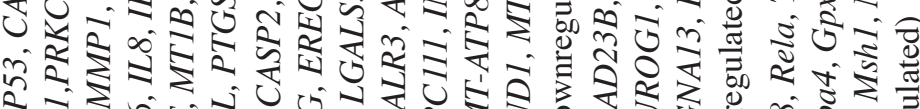

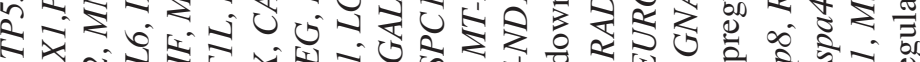

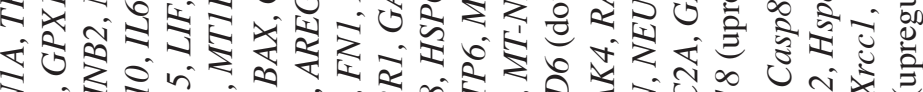
$\sum \vdots 2 n$.

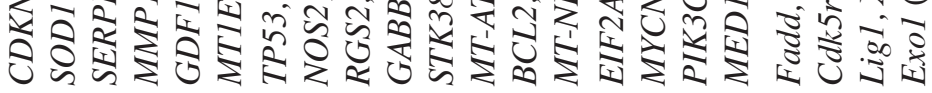

$\underset{త}{\circlearrowright}$

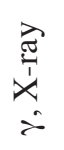

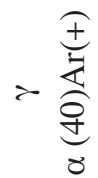


3 -fold in bystander cells compared with controls. GO analysis demonstrated induction of $\mathrm{G}$ protein/phosphoinositide 3-kinase signaling in bystander cell populations. Notably, distinct gene expression profiles were observed in directly IR-hit and bystander fibroblasts, and the results suggested that intercellular communication between IR-exposed and bystander cells could trigger the stress response in bystander cells at the level of transcription.

In one of the first in vivo RIBE studies of heavy-ion particle IR exposures, a Caenorhabditis elegans strain with a green fluorescent protein (GFP) reporter for the $h s p-4$ gene was used (81). When $3 \mathrm{MeV}$ protons were delivered to a specific site in the tail of young worms, GFP expression was enhanced in the posterior intestine after $24 \mathrm{~h}$ in a number dependent manner (with 50 proton hits or more) at distances up to $150 \mu \mathrm{m}$ from the site of IR exposures (81). Notably, these data imply that the RIBE may manifest in vivo at the level of gene expression, and be part of the general stress response.

\section{Conclusions}

The RIBE, as well as other non-targeted effects of IR exposures, have been transforming the radiation biology field in recent decades. The growing body of data suggests that these responses may be triggered by physical and chemical external agents, implying that the RIBE may be part of the general stress response. Such a response is observable at the level of cultured cells, tissues, in vivo explants and in organisms, both vertebrate and invertebrate, implicating the evolutionarily ancient origin of the RIBE. The RIBE signals may transit either through GJIC or through ICM milieu, largely dependent on cell type and radiation quality.

The mechanisms underpinning the RIBE have been studied extensively over the last two decades and many molecules have been proposed to act in RIBE signaling, including ROS and RNS, auxins and ethylene in plants, cytokines, miRNAs and lnRNAs, among others. The epigenetic changes are emerging as the key drivers and effectors of the RIBE. The expression of a number of genes belonging to signaling pathways associated with the cell cycle, DNA damage and DNA repair may be potentiated by the RIBE. With the advent of DNA microarray technique, it has become possible to analyze the gene expression alterations in the RIBE on a high-throughput basis, and numerous studies have illuminated the underlying signaling pathways implicated in the RIBE.

Notably, the emerging data imply that gene expression changes (in mRNAs, miRNAs, mitochondrial RNAs, InRNAs, snoRNAs, among other species) appear to be among the key mechanisms responsible for the RIBE. For example, the activation of the $\mathrm{NF}-\kappa \mathrm{B}$ pathway that was observed in several published reports of the RIBE coincides with the correspondent alterations in gene expression profiles. Interestingly, the p53 signaling network may or may not be responsible for orchestration of the RIBE. The downregulation of hsa-miR-21 is attributable to the RIBE following high-LET IR exposures. In general, IR exposures with $\alpha$-particles result in a robust RIBE with gene expression signatures largely overlapping between directly hit and bystander cells. In marked contrast, low-LET IR exposures mediated through ICM typically appear to lead to modest gene expression changes in the
RIBE with transcriptional profiles being mostly distinct in hit and bystander cells. However, in certain cases, the lack of transcriptional responses may not be associated with the RIBE. The most reports indicate that the transcriptional mechanisms underlying the RIBE following $\alpha$-particle and ${ }^{12} \mathrm{C}$ IR exposures may differ substantially; however, a 28-gene RIBE signature may be a common theme among these exposures (82). The differences and similarities across gene expression changes in the context of the RIBE are presenting in Table I, which summarizes these transcriptional responses as reported in the published literature.

RIBE signal/s generation and transmission generally may be attributable to multiple levels of hierarchy in the context of living matter, including cellular, tissue, organ and whole body/ organism levels. However, there remains to be many discrepancies and a general lack of consensus as to how the RIBE relates to biological effects in exposed living beings. The RIBE is not universal for all cell types, partly because of genetic/epigenetic, environmental and physicochemical factors many of which are still poorly understood. For example, neutron exposure has been shown not to result in the RIBE thus far $(83,84)$.

The RIBE, being part of a broader group of non-targeted effects of IR exposure, is of particular interest in studies of low-dose radiation biology and the combined effects of complex exposures of low-dose IR and chemical pollutants abundant in the environment. However, the major challenge in this field remains the identification of the critical molecules that may serve as a trigger for sending the RIBE signals to non-targeted cells/tissues. Standardized protocols for studying the RIBE need to be developed and established across laboratories along with high-throughput technologies including DNA microarrays, NGS and mass spectrometry to identify the signaling pathways involved. The detailed study of the RIBE in vivo and the development of models for IR risk assessment, employing low doses of IR to account for clinically relevant RIBE, both in diagnostic and therapeutic terms, should be key aims of research in this direction.

\section{Acknowledgements}

Not applicable.

\section{Funding}

The present work was supported by the Intramural Research Program at the Clinical Center National Institutes of Health. This program provided funds for covering the costs to publish in open access.

\section{Availability of data and materials}

Data sharing is not applicable to this article, as no datasets were generated during the current review.

\section{Authors' contributions}

MS designed the review, drafted the manuscript, and agreed to be accountable for all aspects of the manuscript. $\mathrm{RN}$ participated in the review of the manuscript, gave final approval of the manuscript, directed the literature review 
associated with the manuscript, agreed to be accountable for all aspects of the manuscript, aided to draft the manuscript and edited its visual appearance. Both authors read and approved the final manuscript.

\section{Ethics approval and consent to participate}

Not applicable.

\section{Consent for publication}

Not applicable.

\section{Competing interests}

The authors declare that they have no competing interests.

\section{References}

1. Goodhead DT: New radiobiological, radiation risk and radiation protection paradigms. Mutat Res 687: 13-16, 2010.

2. Nagasawa $\mathrm{H}$ and Little JB: Induction of sister chromatid exchanges by extremely low doses of alpha-particles. Cancer Res 52: 6394-6396, 1992.

3. Wu LJ, Randers-Pehrson G, Xu A, Waldren CA, Geard CR, Yu Z and Hei TK: Targeted cytoplasmic irradiation with alpha particles induces mutations in mammalian cells. Proc Natl Acad Sci USA 96: 4959-4964, 1999.

4. Zhou H, Randers-Pehrson G, Waldren CA, Vannais D, Hall EJ and Hei TK: Induction of a bystander mutagenic effect of alpha particles in mammalian cells. Proc Natl Acad Sci USA 97: 2099-2104, 2000.

5. Sawant SG, Randers-Pehrson G, Geard CR, Brenner DJ and Hall EJ: The bystander effect in radiation oncogenesis: I Transformation in $\mathrm{C} 3 \mathrm{H} 10 \mathrm{~T} 1 / 2$ cells in vitro can be initiated in the unirradiated neighbors of irradiated cells. Radiat Res 155 : 397-401, 2001.

6. Mothersill C, Seymour CB and Joiner MC: Relationship between radiation-induced low-dose hypersensitivity and the bystander effect. Radiat Res 157: 526-532, 2002

7. Mitchell SA, Marino SA, Brenner DJ and Hall EJ: Bystander effect and adaptive response in $\mathrm{C} 3 \mathrm{H} 10 \mathrm{~T}(1 / 2)$ cells. Int J Radiat Biol 80: 465-472, 2004.

8. Ponnaiya B, Jenkins-Baker G, Brenner DJ, Hall EJ, Randers-Pehrson G and Geard CR: Biological responses in known bystander cells relative to known microbeam-irradiated cells. Radiat Res 162: 426-432, 2004.

9. Sokolov MV, Smilenov LB, Hall EJ, Panyutin IG, Bonner M and Sedelnikova OA: Ionizing radiation induces DNA double-strand breaks in bystander primary human fibroblasts. Oncogene 24: 7257-7265, 2005.

10. Prise KM, Belyakov OV, Folkard M and Michael BD: Studies of bystander effects in human fibroblasts using a charged particle microbeam. Int J Radiat Biol 74: 793-798, 1998.

11. Huo L, Nagasawa $\mathrm{H}$ and Little JB: HPRT mutants induced in bystander cells by very low fluences of alpha particles result primarily from point mutations. Radiat Res 156: 521-525, 2001.

12. Belyakov OV, Folkard M, Mothersill C, Prise KM and Michael BD: A proliferation-dependent bystander effect in primary porcine and human urothelial explants in response to targeted irradiation. Br J Cancer 88: 767-774, 2003.

13. Dickey JS, Baird BJ, Redon CE, Sokolov MV, Sedelnikova OA and Bonner WM: Intercellular communication of cellular stress monitored by gamma-H2AX induction. Carcinogenesis 30 : 1686-1695, 2009.

14. Sokolov MV and Neumann RD: Radiation-induced bystander effects in cultured human stem cells. PLoS One 5: e14195, 2010.

15. Ghandhi SA, Yaghoubian B and Amundson SA: Global gene expression analyses of bystander and alpha particle irradiated normal human lung fibroblasts: Synchronous and differential responses. BMC Med Genomics 1: 63, 2008.

16. Li F, Liu P, Wang T, Bian P, Wu Y, Wu L and Yu Z: The induction of bystander mutagenic effects in vivo by alpha-particle irradiation in whole Arabidopsis thaliana plants. Radiat Res 174: 228-237, 2010.
17. Xue LY, Butler NJ, Makrigiorgos GM, Adelstein SJ and Kassis AI: Bystander effect produced by radiolabeled tumor cells in vivo. Proc Natl Acad Sci USA 99: 13765-13770, 2002.

18. Persaud R, Zhou H, Hei TK and Hall EJ: Demonstration of a radiation-induced bystander effect for low dose low LET beta-particles. Radiat Environ Biophys 46: 395-400, 2007.

19. Yang H, Magpayo N, Rusek A, Chiang IH, Sivertz M and Held KD: Effects of very low fluences of high-energy protons or iron ions on irradiated and bystander cells. Radiat Res 176: 695-705, 2011.

20. Autsavapromporn N, Suzuki M, Funayama T, Usami N, Plante I, Yokota Y, Mutou Y, Ikeda H, Kobayashi K, Kobayashi Y, et al: Gap junction communication and the propagation of bystander effects induced by microbeam irradiation in human fibroblast cultures: The impact of radiation quality. Radiat Res 180: 367-375, 2013.

21. Shuryak I, Brenner DJ and Ullrich RL: Radiation-induced carcinogenesis: Mechanistically based differences between gamma-rays and neutrons, and interactions with DMBA. PLoS One 6: e28559, 2011.

22. Azzam EI, de Toledo SM, Gooding T and Little JB: Intercellular communication is involved in the bystander regulation of gene expression in human cells exposed to very low fluences of alpha particles. Radiat Res 150: 497-504, 1998.

23. Azzam EI, de Toledo SM and Little JB: Direct evidence for the participation of gap junction-mediated intercellular communication in the transmission of damage signals from alpha -particle irradiated to nonirradiated cells. Proc Natl Acad Sci U S A 98: 473-478, 2001

24. Little JB, Azzam EI, de Toledo SM and Nagasawa H: Bystander effects: Intercellular transmission of radiation damage signals. Radiat Prot Dosimetry 99: 159-162, 2002.

25. Azzam EI, de Toledo SM and Little JB: Expression of CONNEXIN43 is highly sensitive to ionizing radiation and other environmental stresses. Cancer Res 63: 7128-7135, 2003.

26. Olsson MG, Nilsson EJ, Rutardóttir S, Paczesny J, Pallon J and Akerström B: Bystander cell death and stress response is inhibited by the radical scavenger $\alpha(1)$-microglobulin in irradiated cell cultures. Radiat Res 174: 590-600, 2010.

27. Ghandhi SA, Ponnaiya B, Panigrahi SK, Hopkins KM, Cui Q, Hei TK, Amundson SA and Lieberman HB: RAD9 deficiency enhances radiation induced bystander DNA damage and transcriptomal response. Radiat Oncol 9: 206, 2014.

28. Hu B, Shen B, Su Y, Geard CR and Balajee AS: Protein kinase C epsilon is involved in ionizing radiation induced bystander response in human cells. Int J Biochem Cell Biol 41: 2413-2421, 2009.

29. Ghandhi SA, Ming L, Ivanov VN, Hei TK and Amundson SA: Regulation of early signaling and gene expression in the alpha-particle and bystander response of IMR-90 human fibroblasts. BMC Med Genomics 3: 31, 2010.

30. Ghandhi SA, Sinha A, Markatou M and Amundson SA: Time-series clustering of gene expression in irradiated and bystander fibroblasts: An application of FBPA clustering. BMC Genomics 12: 2, 2011.

31. Ivanov VN, Zhou H, Ghandhi SA, Karasic TB, Yaghoubian B, Amundson SA and Hei TK: Radiation-induced bystander signaling pathways in human fibroblasts: A role for interleukin-33 in the signal transmission. Cell Signal 22: 1076-1087, 2010.

32. Kalanxhi E and Dahle J: Transcriptional responses in irradiated and bystander fibroblasts after low dose $\alpha$-particle radiation. Int J Radiat Biol 88: 713-719, 2012.

33. Tian W, Yin X, Wang L, Wang J, Zhu W, Cao J and Yang H: The key role of miR-21-regulated SOD2 in the medium-mediated bystander responses in human fibroblasts induced by $\alpha$-irradiated keratinocytes. Mutat Res 780: 77-85, 2015.

34. Zhang X, Ng WL, Wang P, Tian L, Werner E, Wang H, Doetsch P and Wang Y: MicroRNA-21 modulates the levels of reactive oxygen species by targeting SOD3 and TNFa. Cancer Res 72: 4707-4713, 2012

35. Shao C, Stewart V, Folkard M, Michael BD and Prise KM: Nitric oxide-mediated signaling in the bystander response of individually targeted glioma cells. Cancer Res 63: 8437-8442, 2003.

36. Autsavapromporn N, Plante I, Liu C, Konishi T, Usami N, Funayama T, Azzam EI, Murakami T and Suzuki M: Genetic changes in progeny of bystander human fibroblasts after microbeam irradiation with X-rays, protons or carbon ions: The relevance to cancer risk. Int J Radiat Biol 91: 62-70, 2015.

37. Randers-Pehrson G, Geard CR, Johnson G, Elliston CD and Brenner DJ: The Columbia University single-ion microbeam. Radiat Res 156: 210-214, 2001. 
38. Ponnaiya B, Jenkins-Baker G, Randers-Pherson G and Geard CR: Quantifying a bystander response following microbeam irradiation using single-cell RT-PCR analyses. Exp Hematol 35 (Suppl 1): 64-68, 2007.

39. Rogakou EP, Pilch DR, Orr AH, Ivanova VS and Bonner WM: DNA double-stranded breaks induce histone $\mathrm{H} 2 \mathrm{AX}$ phosphorylation on serine 139. J Biol Chem 273: 5858-5868, 1998.

40. Sokolov MV, Panyutin IG and Neumann RD: Whole-genome gene expression profiling reveals the major role of nitric oxide in mediating the cellular transcriptional response to ionizing radiation in normal human fibroblasts. Genomics 100: 277-281, 2012.

41. Clutton SM, Townsend KM, Walker C, Ansell JD and Wright EG: Radiation-induced genomic instability and persisting oxidative stress in primary bone marrow cultures. Carcinogenesis 17 $1633-1639,1996$

42. Narayanan PK, Goodwin EH and Lehnert BE: Alpha particles initiate biological production of superoxide anions and hydrogen peroxide in human cells. Cancer Res 57: 3963-3971, 1997.

43. Sokolov MV, Dickey JS, Bonner WM and Sedelnikova OA gamma-H2AX in bystander cells: Not just a radiation-triggered event, a cellular response to stress mediated by intercellular communication. Cell Cycle 6: 2210-2212, 2007.

44. Kovalchuk A, Mychasiuk R, Muhammad A, Hossain S, Ilnytskyy S, Ghose A, Kirkby C, Ghasroddashti E, Kovalchuk O and Kolb B: Liver irradiation causes distal bystander effects in the rat brain and affects animal behaviour. Oncotarget 7 : 4385-4398, 2016

45. Zhan Q, Carrier F and Fornace AJ Jr: Induction of cellular p53 activity by DNA-damaging agents and growth arrest. Mol Cell Biol 13: 4242-4250, 1993.

46. Komarova EA, Diatchenko L, Rokhlin OW, Hill JE, Wang ZJ, Krivokrysenko VI, Feinstein E and Gudkov AV: Stress-induced secretion of growth inhibitors: A novel tumor suppressor function of p53. Oncogene 17: 1089-1096, 1998.

47. Albanese J and Dainiak N: Ionizing radiation alters Fas antigen ligand at the cell surface and on exfoliated plasma membrane-derived vesicles: Implications for apoptosis and intercellular signaling. Radiat Res 153: 49-61, 2000.

48. Chaudhry MA: Bystander effect: Biological endpoints and microarray analysis. Mutat Res 597: 98-112, 2006

49. Facoetti A, Ballarini F, Cherubini R, Gerardi S, Nano R, Ottolenghi A, Prise KM, Trott KR and Zilio C: Gamma ray-induced bystander effect in tumour glioblastoma cells: A specific study on cell survival, cytokine release and cytokine receptors. Radiat Prot Dosimetry 122: 271-274, 2006.

50. Kalanxhi E and Dahle J: Genome-wide microarray analysis of human fibroblasts in response to $\gamma$ radiation and the radiation-induced bystander effect. Radiat Res 177: 35-43, 2012.

51. Chaudhry MA and Omaruddin RA: Differential regulation of microRNA expression in irradiated and bystander cells. Mol Biol (Mosk) 46: 634-643, 2012.

52. Hu W, Xu S, Yao B, Hong M, Wu X, Pei H, Chang L, Ding N, Gao X, Ye C, et al: miR-663 inhibits radiation-induced bystander effects by targeting TGFB1 in a feedback mode. RNA Biol 11: $1189-1198,2014$

53. Xu S, Ding N, Pei H, Hu W, Wei W, Zhang X, Zhou G and Wang J: miR-21 is involved in radiation-induced bystander effects. RNA Biol 11: 1161-1170, 2014.

54. Tabe Y, Hatanaka Y, Nakashiro M, Sekihara K, Yamamoto S, Matsushita H, Kazuno S, Fujimura T, Ikegami T, Nakanaga K, et al: Integrative genomic and proteomic analyses identifies glycerol-3-phosphate acyltransferase as a target of low-dose ionizing radiation in EBV infected-B cells. Int J Radiat Biol 92: 24-34, 2016.

55. Chaudhry MA and Omaruddin RA: Mitochondrial gene expression in directly irradiated and nonirradiated bystander cells. Cancer Biother Radiopharm 26: 657-663, 2011.

56. Chaudhry MA: Small nucleolar RNA host genes and long non-coding RNA responses in directly irradiated and bystander cells. Cancer Biother Radiopharm 29: 135-141, 2014.

57. Furlong H, Mothersill C, Lyng FM and Howe O: Apoptosis is signalled early by low doses of ionising radiation in a radiation-induced bystander effect. Mutat Res 741-742: 35-43, 2013.

58. Ghosh S, Maurya DK and Krishna M: Role of iNOS in bystander signaling between macrophages and lymphoma cells. Int J Radiat Oncol Biol Phys 72: 1567-1574, 2008.

59. Rzeszowska-Wolny J, Herok R, Widel M and Hancock R: $\mathrm{X}$-irradiation and bystander effects induce similar changes of transcript profiles in most functional pathways in human melanoma cells. DNA Repair (Amst) 8: 732-738, 2009.
60. Herok R, Konopacka M, Polanska J, Swierniak A, Rogolinski J, Jaksik R, Hancock R and Rzeszowska-Wolny J: Bystander effects induced by medium from irradiated cells: Similar transcriptome responses in irradiated and bystander K562 cells. Int J Radiat Oncol Biol Phys 77: 244-252, 2010.

61. Faqihi F, Neshastehriz A, Soleymanifard S, Shabani R and Eivazzadeh N: Radiation-induced bystander effect in non-irradiated glioblastoma spheroid cells. J Radiat Res (Tokyo) 56: 777-783, 2015.

62. Asur RS, Sharma S, Chang CW, Penagaricano J, Kommuru IM, Moros EG, Corry PM and Griffin RJ: Spatially fractionated radiation induces cytotoxicity and changes in gene expression in bystander and radiation adjacent murine carcinoma cells. Radiat Res 177: 751-765, 2012.

63. Yuan D, Xu J, Wang J, Pan Y, Fu J, Bai Y, Zhang J and Shao C: Extracellular miR-1246 promotes lung cancer cell proliferation and enhances radioresistance by directly targeting DR5. Oncotarget 7: 32707-32722, 2016.

64. Babini G, Bellinzona VE, Morini J, Baiocco G, Mariotti L, Unger K and Ottolenghi A: Mechanisms of the induction of apoptosis mediated by radiation-induced cytokine release. Radiat Prot Dosimetry 166: 165-169, 2015.

65. Widel M, Lalik A, Krzywon A, Poleszczuk J, Fujarewicz K and Rzeszowska-Wolny $\mathrm{J}$ : The different radiation response and radiation-induced bystander effects in colorectal carcinoma cells differing in p53 status. Mutat Res 778: 61-70, 2015.

66. Wu J and Izpisua Belmonte JC: Stem Cells: A Renaissance in Human Biology Research. Cell 165: 1572-1585, 2016.

67. Banaz-Yaşar F, Lennartz K, Winterhager E and Gellhaus A: Radiation-induced bystander effects in malignant trophoblast cells are independent from gap junctional communication. J Cell Biochem 103: 149-161, 2008.

68. Sugihara T, Murano H, Nakamura M and Tanaka K: In vivo partial bystander study in a mouse model by chronic medium-dose-rate $\gamma$-ray irradiation. Radiat Res 179: 221-231, 2013.

69. Müller WE, Ushijima H, Batel R, Krasko A, Borejko A, Müller IM and Schröder HC: Novel mechanism for the radiation-induced bystander effect: Nitric oxide and ethylene determine the response in sponge cells. Mutat Res 597: 62-72, 2006.

70. Yang G, Wu L, Chen L, Pei B, Wang Y, Zhan F, Wu Y and Yu Z Targeted irradiation of shoot apical meristem of Arabidopsis embryos induces long-distance bystander/abscopal effects. Radiat Res 167: 298-305, 2007.

71. Li F, Wang T, Xu S, Yuan H, Bian P, Wu Y, Wu L and Yu Z: Abscopal mutagenic effect of low-energy-ions in Arabidopsis thaliana seeds. Int J Radiat Biol 87: 984-992, 2011.

72. Wang T, Sun Q, Xu W, Li F, Li H, Lu J, Wu L, Wu Y, Liu M and Bian P: Modulation of modeled microgravity on radiation-induced bystander effects in Arabidopsis thaliana. Mutat Res 773: 27-36, 2015.

73. Wang T, Xu W, Deng C, Xu S, Li F, Wu Y, Wu L and Bian P: A pivotal role of the jasmonic acid signal pathway in mediating radiation-induced bystander effects in Arabidopsis thaliana. Mutat Res 791-792: 1-9, 2016

74. Wang T, Li F, Xu S, Bian P, Wu Y, Wu L and Yu Z: The time course of long-distance signaling in radiation-induced bystander effect in vivo in Arabidopsis thaliana demonstrated using root micro-grafting. Radiat Res 176: 234-243, 2011.

75. Aravindan S, Natarajan M, Ramraj SK, Pandian V, Khan FH, Herman TS and Aravindan N: Abscopal effect of low-LET $\gamma$-radiation mediated through Rel protein signal transduction in a mouse model of nontargeted radiation response. Cancer Gene Ther 21: 54-59, 2014.

76. Kovalchuk O, Zemp FJ, Filkowski JN, Altamirano AM, Dickey JS, Jenkins-Baker G, Marino SA, Brenner DJ, Bonner WM and Sedelnikova OA: microRNAome changes in bystander three-dimensional human tissue models suggest priming of apoptotic pathways. Carcinogenesis 31: 1882-1888, 2010.

77. Szatmári T, Kis D, Bogdándi EN, Benedek A, Bright S, Bowler D, Persa E, Kis E, Balogh A, Naszályi LN, et al: Extracellular Vesicles Mediate Radiation-Induced Systemic Bystander Signals in the Bone Marrow and Spleen. Front Immunol 8: 347, 2017.

78. Koturbash I, Zemp FJ, Kutanzi K, Luzhna L, Loree J, Kolb B and Kovalchuk O: Sex-specific microRNAome deregulation in the shielded bystander spleen of cranially exposed mice. Cell Cycle 7: 1658-1667, 2008.

79. Cai S, Shi GS, Cheng HY, Zeng YN, Li G, Zhang M, Song M, Zhou PK, Tian Y, Cui FM, et al: Exosomal miR-7 Mediates Bystander Autophagy in Lung after Focal Brain Irradiation in Mice. Int J Biol Sci 13: 1287-1296, 2017. 
80. Iwakawa M, Hamada N, Imadome K, Funayama T, Sakashita T, Kobayashi Y and Imai T: Expression profiles are different in carbon ion-irradiated normal human fibroblasts and their bystander cells. Mutat Res 642: 57-67, 2008.

81. Bertucci A, Pocock RD, Randers-Pehrson G and Brenner DJ: Microbeam irradiation of the $C$. elegans nematode. J Radiat Res 50: A49-A54, 2009.

82. Yeles C, Vlachavas EI, Papadodima O, Pilalis E, Vorgias CE, Georgakilas AG and Chatziioannou A: Integrative Bioinformatic Analysis of Transcriptomic Data Identifies Conserved Molecular Pathways Underlying Ionizing Radiation-Induced Bystander Effects (RIBE). Cancers (Basel) 9: 9, 2017.
83. Wang C, Smith RW, Duhig J, Prestwich WV, Byun SH, McNeill FE, Seymour CB and Mothersill CE: Neutrons do not produce a bystander effect in zebrafish irradiated in vivo. Int J Radiat Biol 87: 964-973, 2011.

84. Seth I, Schwartz JL, Stewart RD, Emery R, Joiner MC and Tucker JD: Neutron exposures in human cells: Bystander effect and relative biological effectiveness. PLoS One 9: e98947, 2014.

(i) (3) This work is licensed under a Creative Commons Attribution-NonCommercial-NoDerivatives 4.0 International (CC BY-NC-ND 4.0) License. 